\title{
Scale-Up Production Of Extracellular Vesicles From Mesenchymal Stromal Cells Isolated From Pre- Implantation Equine Embryos
}

\section{Zoe Tasma}

University of Auckland

\section{Weilin Hou}

University of Auckland

Tanvi Damani

University of Auckland

Katy Seddon

University of Auckland

Matthew Kang

University of Auckland

Yi Ge

University of Auckland

David Hanlon

Colorado State University

Fiona Hollinshead

Colorado State University

Colin L. Hisey ( $\nabla$ hisey.12@osu.edu )

The Ohio State University

Lawrence W. Chamley

University of Auckland

\section{Research Article}

Keywords: Mesenchymal stromal cell, Extracellular vesicle, Exosome, Microvesicle, Bioreactor, Equine, Embryo, Celline AD 1000, Fibercell

Posted Date: March 2nd, 2022

DOI: https://doi.org/10.21203/rs.3.rs-1362793/v1

License: (c) (1) This work is licensed under a Creative Commons Attribution 4.0 International License.

Read Full License 


\section{Abstract}

Mesenchymal stromal cells (MSC) have recently been explored for their potential use as therapeutics in veterinary medicine applications. Alternatively, MSC-derived extracellular vesicles (EVs) may also provide therapeutic benefits but as an off-the-shelf solution, provided they can be produced in large enough quantities and without the risk of contamination from bovine EVs contained in fetal bovine serum that is a common component of cell culture media. Towards this aim, we demonstrated the successful isolation and characterisation of equine MSCs from pre-implantation embryos. We also demonstrate that many of these lines can be propagated long-term in culture and conducted a head-to-head comparison of two bioreactor systems for scalable EV production including in serum-free conditions. Based on our findings, the CELLine ${ }^{T M} A D 1000$ flasks enabled higher cell density cultures and significantly more EV production than the Fibercell ${ }^{\mathrm{TM}}$ system or conventional culture flasks. These findings will enable future isolation of equine MSCs and the scalable culture of their EVs for a wide range of applications in this rapidly growing field.

\section{Introduction}

Mesenchymal stromal cells (MSCs) have recently been used as therapeutics in several experimental settings including veterinary applications. Typically, MSCs express CD73, CD90, and CD105 cell surface markers, adhere to plastic, and can be differentiated into three lineages, but lack hematopoietic and endothelial markers ${ }^{1,2}$. In veterinary applications it is common to conduct autologous MSC transplantation, in which MSCs are isolated from the animal to be treated, expanded by in vitro culture, then transferred back to the original animal ${ }^{3}$. This process is invasive to the animals and due to the time required to expand MSCs in vitro, may delay treatment and potentially reduce the effectiveness of MSC therapy. Therefore, an off-the-shelf product that could be used in allotransplantation may be advantageous. There is considerable and growing evidence that the anti-inflammatory and regenerative properties of MSCs are not the result of engraftment of the MSCs themselves, but rather are affected by extracellular vesicles (EVs) extruded from the MSCs ${ }^{3,4}$.

EVs are lipid membrane bound vesicles that are released from all cells ${ }^{5}$. They contain cargos of proteins, DNA and RNA, including short and long regulatory RNAs ${ }^{6,7}$. Compared to live cells, EVs have several advantages as a therapeutic agent. EVs are not live cells and therefore, present no risk of unintentional growth at sites of engraftment and appear to be less antigenic than the cells from which they are derived 7,8 . However, a major problem facing EV researchers is the limited yield of EVs from conventional cell culture systems, particularly from primary cells. This is a significant obstacle in the preparation of EVs, especially for the production of a large scale, off-the-shelf therapeutics. A further barrier to obtaining large quantities of MSC-derived EVs is that cultures typically utilize fetal calf serum, which itself contains many EVs that cannot be effectively separated from the MSC-derived EVs ${ }^{9}$. 
Bioreactors that support high-density culture may be a solution to both EV yield and contaminating exogenous serum EV problems. Some devices use semipermeable membranes to separate the bioreactors into a large volume medium chamber and a small cell chamber. The membrane allows transfer of essential nutrients to the cells while preventing the exchange of larger products such as EVs between the compartments. At the same time, EVs extruded from the cells are concentrated in the smaller volume cell compartment, reducing downstream isolation requirements. Examples of such bioreactors include the FiberCell ${ }^{T M}$ system that is based on semipermeable hollow-fibers through which medium is pumped and the CELLine ${ }^{\mathrm{TM}}$ system that has static media in two chambers separated by a semipermeable membrane. While both systems were developed for hybridoma cell culture for production of monoclonal antibodies in the past, they have recently been reported for EV harvesting from cell lines ${ }^{10-16}$. However, a direct comparison of these two types of bioreactors for the preparation of EVs from primary cultures of MSCs has not yet been undertaken.

In this study, we report the isolation, culture, and characterisation of cells from pre-implantation equine embryos that display characteristics of MSCs. We were then able to grow these cells in CELLine ${ }^{\text {TM }}$ and FiberCell $^{\mathrm{TM}}$ bioreactors in the absence of FBS and compared EV yield from these systems to conventional cultures. To the best of our knowledge, this is the first example of culturing equine MSCs in bioreactor systems for the large-scale production of EVs.

\section{Results}

\section{Isolation and characterisation of equine MSC-like cells}

We isolated putative MSC lines from six equine pre-implantation embryos based on plastic adhesion. While the cultures initially contained multiple cell types, cells with the morphology of MSCs rapidly became the predominant cell type due to their high rate of proliferation. Very few non-MSCs survived passage to fresh flasks and by passage three, the cultures were essentially pure (Fig. 1). We continued to passage the cells to monitor when they would cease proliferation. Three of the lines (PL, T, and DP) stopped rapid proliferation between passages 8-11, two lines ( $\mathrm{J}$ and FM) continued proliferating to passage 20-21 but the proliferation rate of FM slowed from passage 16. One line (SF) continued to proliferate to passage 32 .

Figure 1. Phase-contrast photomicrograph demonstrating the morphology of the MSC-like cells cultured from equine pre-implantation embryos. Image taken using a $4 x$ non-confocal objective. Scale bar, 500 $\mu \mathrm{m}$.

\section{Lineage markers suggest MSCs}

To investigate if the cultured equine embryo-derived cells exhibited MSC-like phenotypes, the expression of MSC markers was examined for the three cell lines that grew beyond passage 11. Flow cytometry and RT-PCR confirmed the expression of CD90 and CD44 (Fig. 2 Table S3), while due to the absence of suitable antibodies the expression of CD73 and CD105 were demonstrated by RT-PCR (Fig. 2, Table S3) ${ }^{1}$. 
Cells were additionally found to weakly express class I MHC. An additional marker, CD146 was shown to be strongly expressed by the MSCs by quantitative RT-PCR but, levels of CD146 declined in very late passages of each cell line (Table S3) ${ }^{17}$.

We continued characterisation of MSC-like cells using flow cytometry which confirmed the absence of CD14 and MHC-class II markers from all three cell lines (Fig. 2). Flow cytometry suggested very weak expression of CD45 in some passages for two of the three MSC lines but RT-PCR confirmed the absence of CD45 expression (Fig. 2, Table S3). Quantitative RT-PCR also confirmed low or no CD31 expression and low CD34 expression that declined overtime in culture (Fig. 2, Table S3).

In summary, our MSC-like cells expressed CD90, CD105, CD73, CD44, and CD146 but did not express CD14, CD34 CD45, and MHC-class II consistent with the characteristic phenotype of MSCs.

\section{Trilineage differentiation assays confirm MSCs}

Cultured MSCs have the ability to differentiate into three mesenchymal lineages: adipogenic, osteogenic and chrondrogenic. To further investigate whether the equine embryo-derived cells were MSCs, cells from the three lines were incubated in media for 14 or 21 days to stimulate differentiation and representative images at day 21 are presented (Fig. 3). Adipogenic differentiation was confirmed by positive staining with Oil Red-O and no lipid droplet formation was detected in control untreated cells (Fig. 3A, Table S4). Following incubation in osteogenic differentiation conditions the cells showed a pronounced change in morphology (Figure S3A) accompanied by the presence of Alizarin Red S-stained calcium deposits; however, this staining was variable between cell lines and passages (Fig. 3B, Table S4). Chondrogenic differentiation was confirmed by altered morphology and larger cell pellet, in addition to increased Alcian Blue staining (Fig. 3C, Figure S3B).

\section{Equine embryo-derived MSCs cultured in high-density bioreactors}

The yield of EVs from MSCs cultured in traditional flat surfaces is not practical or scalable enough for use as a therapeutic. To improve the yield of EVs we tested the ability of one cell line (SF) to grow in bioreactors under serum-free conditions to avoid contamination of MSC-derived EVs with exogenous bovine serum EVs (Fig. 4A).

Two different bioreactors were tested in this study, including a $1 \mathrm{~L} \mathrm{CELLine}{ }^{\mathrm{TM}}$ flask for adherent cells and a FiberCell $^{\mathrm{TM}}$ with two different hollow fiber cartridges, 2025D and 2025G. The 2025D was coated with fibronectin to help improve cell adhesion. The cells were seeded into the bioreactors in DMEM/F12 containing 10\% FBS and cultured for 27 days to establish the high-density cultures. Direct observation of the cells was not possible in any of the bioreactors. Therefore, glucose consumption was used as an indirect measure for cell growth. An increase in daily glucose consumption was observed in the CELLine ${ }^{\text {Tm }}$ flask in this establishment phase of the culture, but there was no increase in glucose consumption in either cartridge in the FiberCell ${ }^{\mathrm{TM}}$ system (Fig. 5A). At the end of the growth period, the bioreactors were 
dismantled to assess cell density and surface morphology. Although we did not attempt to quantify cell numbers, cells covered most of the mesh surface within the CELLine ${ }^{T M}$ flask with very little exposed surface (Fig. 5B). DAPI staining confirmed the presence of densely packed cells which were absent in an unused flask. Little biomaterial was found on the semipermeable dialysis membrane and the gaspermeable plastic sheets underneath the fibrous growth surface (Figure S4). In contrast, SEM of both Fibercell ${ }^{\mathrm{TM}}$ systems indicated the presence of relatively sparse cell clusters with limited coverage of the fiber surface (Fig. 5C).

\section{CELLine $^{\mathrm{m}}$ AD 1000 bioreactor supports high EV production}

After 27 days in FBS containing medium we changed to media with CDM-HD serum replacement and began harvesting EVs. EV were harvested from the CELLine ${ }^{\mathrm{TM}}$ flask at a stable rate ranging from 4-10 $\mathrm{x} 10^{10}$ particles/day. On average, this is approximately equal to the number of EVs produced by MSCs grown in 20 T175 flasks. In contrast, both cartridges in the FiberCell ${ }^{T M}$ system produced only $0.1-0.6$ $\mathrm{x} 10^{10} \mathrm{EVs} /$ day, which is approximately the same number of EVs produced by MSCs grown in one T175 flask. Nanoparticle tracking analysis (NTA) indicated that the average EV size ( $100 \mathrm{~nm})$ was similar regardless of the culture system used (Fig. 6B,C), and TEM images of EVs from the CELLine ${ }^{\text {TM }}$ flask show the expected rounded and cup-like morphologies (Fig. 6D). Lower magnification TEM images, as required by the MISEV guidelines, are presented in Figure S6.

Due to the low EV production, the Fibercell ${ }^{\mathrm{TM}}$ system was terminated after 46 days of culture while the $\mathrm{CELLine}^{\mathrm{TM}}$ system was maintained to examine if cells could survive and continue to produce EVs with different medium combinations. To do this, the medium in the large chamber was changed to advanced DMEM/F12 with $2 \%$ FBS and the medium in cell chamber was changed to basal DMEM/F12 without FBS or CDM-HD. Cells were cultured for additional 4 weeks and after an initial rise, EV production was maintained at an average $6 \times 10^{10} /$ day, similar to that observed when the cell chamber medium contained the CDM-HD serum replacement (Figure S5).

\section{Extracellular vesicles cannot pass between chambers of the CELLine $^{\mathrm{m} \mathrm{m}}$ flask}

The CELLine ${ }^{\mathrm{TM}}$ flask system has a large $(\sim 1 \mathrm{~L})$ chamber that contains growth medium and a much smaller $15 \mathrm{~mL}$ cell chamber into which EVs are secreted (Fig. 4). In theory, the semipermeable membrane that separates the chambers should prevent any bovine serum EVs from the growth medium chamber passing into the lower cell chamber from which EVs are harvested. To test this, we added $500 \mathrm{~mL}$ Advanced DMEM/F12 containing 2\% FBS to the growth medium chamber and $15 \mathrm{~mL}$ of PBS to the lower chamber of three fresh CELLine ${ }^{\mathrm{TM}}$ flasks without cells. Following three days of incubation at $37^{\circ} \mathrm{C}, \mathrm{NTA}$ analysis indicated there were $1.14 \times 10^{9}\left(+/-1.36 \times 10^{7}\right)$ particles/13 mLs of medium in the large chamber and $3.44 \times 10^{7}\left(+/-4.13 \times 10^{7}\right)$ particles/13 $\mathrm{mLs}$ in the lower chamber indicating that despite a substantial concentration gradient, EVs were unable to pass through the semipermeable membrane (Table S5). 


\section{The economics of using the CELLine ${ }^{\mathrm{m}}$ bioreactor for EV production}

There is an initial cost of approximately $\$($ US $) 400$ to purchase a single CELLine ${ }^{\text {TM }}$ flask or Fibercell ${ }^{T M}$ cartridge. The FiberCell ${ }^{\text {Tw }}$ system requires an additional one-off investment in the pump required to circulate the medium. The daily yield of EVs from our cells grown in the CELLine ${ }^{\text {TM }}$ system was approximately 20 time the yield from traditional T175 flasks. Assuming one medium change and one passage per week, between 1-2 days of technician time would be required to maintain the 20 T175 flasks. In contrast, only 1-2 hrs/week was required to maintain the CELLine ${ }^{T \mathrm{~T}}$ system. There is also a considerably reduced environmental impact from the use of a single bioreactor which we maintained for approximately three months compared to the use of 20 T175 flasks which are traditionally replaced after each passage. Furthermore, the CELLine ${ }^{\mathrm{Tm}}$ flask provides EVs in much lower volume, potentially reducing the total isolation and purification time and cost depending on the specific downstream application. A comparison of the costs of generating equivalent numbers of EVs bioreactors and conventional flasks is presented in Table 1.

Table 1

Cost and efficiency comparison of CELLine ${ }^{\mathrm{TM}}$, FiberCell $^{\mathrm{TM}}$ and traditional culturing system.

\begin{tabular}{|c|c|c|c|}
\hline & CELLine $^{\mathrm{m}}$ & Fibercell $^{\mathrm{m}}$ & T175 \\
\hline Length of culture & 82 days & 46 days & Passage every $3-4$ days \\
\hline Price (USD) & 345.8 & $\begin{array}{l}321(\text { small } \\
\text { cartridge) }\end{array}$ & $\begin{array}{l}70.6(20 \mathrm{~T} 175 \text { for } 1 \\
\text { passage) }\end{array}$ \\
\hline Medium/Week & $500 \mathrm{ml}$ & $500 \mathrm{ml}$ & At least $1 \mathrm{~L}$ \\
\hline $\begin{array}{l}\text { TC work cost/week (USD } 2 \\
\text { harvests) }\end{array}$ & $\begin{array}{l}17.6(1 \\
\mathrm{hr})\end{array}$ & $\begin{array}{l}17.6-35.2(1-2 \\
\text { hrs })\end{array}$ & $140.85-281.7$ ( $1-2$ days $)$ \\
\hline \multicolumn{4}{|c|}{${ }^{1}$ need additional cost for pump } \\
\hline \multicolumn{4}{|c|}{${ }^{2}$ value was calculated based on a technician's salary of (\$NZ) 60,000/year } \\
\hline
\end{tabular}

\section{Discussion}

Mesenchymal stromal cells are typically isolated from adipose tissue or bone marrow, but numerous other sources of MSCs have been described, including the placenta, endometrium, and cord blood ${ }^{18-20}$. It has been suggested that MSCs obtained from younger tissues, such as placentae, have greater differentiation potential, are more anti-inflammatory, and may proliferate longer in culture than cells derived from older tissues ${ }^{20,21}$. Here, we isolated multiple MSC-like lines from several preimplantation equine embryos. These lines all proliferated at a high rate when initially isolated, but several lines continued to rapidly proliferate beyond passage 11 which is much higher than previously isolated equine 
MSCs ${ }^{22}$. This continued proliferation of embryo-derived cells in culture is a significant advantage if these cells are used as a source of MSCs or their EVs for regenerative medicine.

There are clear criteria, issued by the International Society for Cell Therapy that human cells need to meet before they are considered MSCs ${ }^{23}$. However, it is less clear whether equine MSCs fit all of these criteria and this is further complicated by the limited availability of characterised reagents to interrogate these markers ${ }^{24}$. The isolated embryo-derived MSC-like cells in the current study expressed markers typical of equine MSCs and lacked hematopoietic markers, comparable to previous reports of the characterisation of MSCs derived from equine adipose, bone marrow, placenta, and umbilical cord blood ${ }^{25-27}$. The low or variable expression of CD34 and CD73 observed in the current study was not unexpected and indicates potential differences between MSCs from human and equine origins ${ }^{25,26}$. Although it was confirmed that embryo-derived MSCs do not express the CD45 hematopoietic marker, the variable low expression observed by flow cytometry confirms the problematic nature of some antibodies for some less commonly researched species such as equids. In addition to the classical MSC panel of markers, prior studies have also reported the expression of CD146, a marker suggested to identify MSCs with higher multipotency, which the embryo-derived MSC-like cells in the current study strongly expressed ${ }^{17,28}$. Expression of this marker indicates that the cells within this study may have the potential to treat a wider range of conditions than classical MSCs.

An important secondary characteristic of MSCs is their ability to differentiate into multiple lineages. Comparable to prior studies, the equine embryo-derived cells readily underwent differentiation to adipocytes. However, other studies have suggested that this requires modification to typical media, especially the addition of rabbit serum ${ }^{22,24,26}$. Like placental MSCs, these embryo-derived cells were less inclined to commit to the osteogenic lineage than bone marrow-derived MSCs ${ }^{29}$. Similarly, cells in chondrogenic differentiation medium underwent clear morphologic changes but showed variable staining with Alcian blue. Overall, the expression of MSC markers, lack of lineage-specific markers and ability to undergo differentiation suggests the equine embryo-derived cells are MSCs.

In many cases, MSCs used in equine regenerative medicine are derived from either bone marrow or adipose tissue of the animal that is being treated ${ }^{30,31}$. This requires invasive extraction of tissue or cells from the animal and due to the low numbers of MSCs, these cells are then expanded in vitro in a lengthy process that takes approximately 1-2 weeks. The enriched MSCs are then used to treat the animal. There is potentially considerable therapeutic and economic value in being able to treat these animals at a time more proximal to the time of injury. Having a ready source of allogeneic MSCs with high regenerative potential available that could be rapidly accessed would achieve more timely treatment of injured animals, as previously described for the use of human MSCs ${ }^{32}$. Since our MSCs are derived from young tissues it is likely that they will also possess more anti-inflammatory and regenerative properties than the adult MSCs that are used in current practice and they could potentially a valuable allogeneic therapeutic. 
The utility of MSCs in regenerative medicine has been recognised for many years. However, in more recent times it was noted that there is a failure of large-scale engraftment of the MSCs and attention has focused more on the beneficial effects of the factors that these cells release ${ }^{33-37}$. In this light, EVs are of particular interest, since they are thought to convey many of the anti-inflammatory and regenerative properties of MSCs and appear to be amenable to long-term storage ${ }^{3,4}$. Reflecting this, there are more than 1300 registered trials of MSCs for various conditions and a growing number of clinical trials that investigate the use of EVs from MSCs as a therapeutic treatment (https://clinicaltrials.gov/ct2/home assessed 15th November 2021). MSC-derived EVs have shown value in veterinary medicine as therapies for persistent mating-induced endometritis, increasing oocyte yield, as well as in many non-reproductive conditions such as osteoarthritis and tendonitis ${ }^{38-40}$ and there is potential that EVs from our equine embryo-derived MSCs would also show similar benefits ${ }^{41-43}$.

A major limitation to the use of EVs as a therapeutic is the limited capacity of MSCs to produce EVs in traditional two-dimensional culture flasks. Small bioreactors have been used for purposes such as monoclonal antibody production for many years and more recently investigators have started to explore their use for the production of EVs ${ }^{10,44}$. Here we conducted a head-to-head comparison of two common, commercially available small bioreactor systems, the CELLine ${ }^{T M}$ flask system and the FiberCell ${ }^{T M}$ system. These systems use two different growth surfaces and the CELLine ${ }^{\text {TM }}$ flask is static while the FiberCell ${ }^{\text {TM }}$ uses a continuous flow of media. In this comparison, the CELLine ${ }^{\mathrm{TM}}$ flask system clearly outperformed the FiberCell $^{\mathrm{TM}}$ in terms of cell density and quantity of EVs produced. Guerreiro et al. reported the use of CELLine $^{\text {TM }}$ flask with PE/CA-PJ49/E10; BxPC3 and H3 cell lines ${ }^{15}$. Similar to our observation, in that study and others, adherent cells grew well in CELLine ${ }^{\mathrm{TM}}$ and produce EVs in range of $10^{10}$ particles/harvest ${ }^{11,15}$. The MSC line that we isolated and trailed adapted well to culture in the CELLine ${ }^{\mathrm{TM}}$ flask and showed the potential to allow long term, stable, EV production. Moreover, this production was sustained in the absence of FBS in the cell chamber. In contrast to the report of Guerreiro et al ${ }^{15}$, our MSCs mainly attached to and grew on the mesh net rather than spread to the semipermeable membrane or plastic sheets in the CELLine ${ }^{\text {TM }}$ flask. This suggested the behaviour of cells in the bioreactors is likely to be cell type/line dependent. While there was little attachment of our MSCs to either of the growth surfaces in the FiberCell $^{\text {Tm }}$ systems we tested, it is possible that other surfaces or hollow fibre cartridges might be more suited to adherent cell growth. We have for many years used, and continue to use, the FiberCell ${ }^{\mathrm{Tm}}$ system to produce monoclonal antibodies in serum-free conditions from hybridoma cells. It may be that the FiberCell ${ }^{\text {TM }}$ system might be more successful in producing EVs from non-adherent cells such as lymphocytes.

One real highlight of using bioreactors is the potential to harvest large numbers of EVs that are free from contaminating bovine EVs derived from FBS. In the CELLine ${ }^{T M}$ flask system this can be achieved using either a serum replacement or a combination of serum-containing medium in the large medium compartment and serum-free medium in the cell growth compartment from which EVs are harvested. Here we confirmed using flasks without cells, that the semipermeable membrane does indeed prevent the passage of EVs from the large medium chamber to the small cell chamber of the CELLine ${ }^{\mathrm{TM}}$ flask system. 
Other major advantages of using the CELLine ${ }^{\text {TM }}$ bioreactor that we have characterised are; 1 ) substantially reducing the person time required to maintain the culture and harvest EVs, 2) a substantial reduction in environmental impact by reducing the number of flasks and other disposable culture consumables required, and 3) a major reduction in the cost of cell culture and EV processing consumables. Although culturing of MSCs using bioreactors is beneficial, there are also drawbacks to their current designs. Neither of the systems used in the current study provided any visual access point to check the health and/or growth of adherent cells in the bioreactors. Although, as used here, glucose consumption may provide some insight to the cell's metabolic activity, it may not always represent the actual growth of the cells, particularly when using a commercial serum replacement, which may contain an alternative energy source. Finally, it has recently been shown that changing the growth conditions of MSCs or other cells following adaptation to culture in bioreactors altered the contents and therefore possibility the biological function of EVs ${ }^{45}$.

In this study, we demonstrate that a novel source of MSCs can be isolated from pre-implantation equine embryos, that the isolated cells express characteristic MSC markers and can be differentiated into the expected three lineages. In addition, given the recent interest in using MSC-derived EVs in therapeutic applications, we tested the performance of the MSCs in two commonly reported small bioreactor systems for EV production. Based on our findings, the CELLine ${ }^{\mathrm{TM}}$ AD 100 bioreactor flask outperformed both conventional culture systems and the two Fibercell cartridges tested, in supporting high cell density and total EV production. We hope these findings will encourage further exploration of these novel MSCs and their EVs in veterinary regenerative medicine research. Furthermore, we hope our findings on different bioreactor culture systems will enable researchers to produce EVs in quantities that will ultimately facilitate clinical therapeutic application in veterinary medicine at a commercial level.

\section{Methods}

\section{Materials}

Culture medium and additives were purchased from Gibco ${ }^{\text {TM }}$ (Thermo Fisher Scientific, NZ) unless indicated otherwise. PBS (CAT.D8537) was supplied from Sigma-Aldrich (USA). Primary and secondary antibodies for flow cytometry are as described in Table S1. FiberCell cartridges and CDM-HD were purchased from the FiberCell System (USA) and the CELLine AD 1000 flasks from Sigma-Aldrich (MO, USA).

\section{Isolation and culture of pre-implantation equine embryo MSC}

The mesenchymal stromal cells used in this study were isolated from 33-34 day old equine embryos produced in our laboratory (ethics approval AEC1431). The embryos were harvested following the method of de Mestre, et al. ${ }^{46}$. Equine embryos were transported in PBS with $2 \%$ anti-anti until processed. Equine embryos were examined under a dissecting microscope and any fetal membrane removed. The embryos 
were minced with a scalpel then passed through a $2 \mathrm{~mm}$ stainless steel mesh and 1/10 of the cells used for subsequent culture. Cells were initially cultured and characterised in DMEM/F12 containing $150 \mathrm{mM}$ HEPES, 10\% FBS (Life Technologies, NZ), $0.4 \mu \mathrm{g} / \mathrm{ml}$ insulin (Sigma-Aldrich), 1\% anti-anti, 1\% GlutaMAX, and $0.5 \mathrm{\mu g} / \mathrm{ml}$ Vitamin $\mathrm{C}$ (Sigma-Aldrich), and grown in a humidified incubator at $37^{\circ} \mathrm{C}$ with $5 \% \mathrm{CO}_{2}$. Cells were subsequently cultured in Advanced DMEM/F12 supplemented with $2 \% \mathrm{FBS}, 1 \%$ anti-anti and $1 \%$ GlutaMAX in T75 filter-cap flasks. Cells were passaged with $0.05 \%$ Trypsin for RNA extraction and differentiation assays or detached using TrypLE or accutase for flow cytometry experiments.

\section{cDNA synthesis, RT-PCR and quantitative RT-PCR}

RNA was extracted from 1 million equine MSC-like cells or PBMCs using TriZol and the PureLink RNA mini kit (Invitrogen, MA, USA). RNA was reverse-transcribed to cDNA using the the qScript cDNA Supermix (Quanta Biosciences, MD, USA) or the High-capacity RNA-to-cDNA kit (Applied Biosystems, MA, USA) as per the manufacturer's instructions.

RT-PCR experiments were performed using the EmeraldAmp Max HS PCR master mix (Takara, Japan) as per the manufacturer's instructions. Briefly, $1 \mu \mathrm{L} \mathrm{cDNA}(<50 \mathrm{ng} / \mu \mathrm{L})$ was added to $10 \mu \mathrm{L}$ Emerald Master Mix, $0.5 \mu \mathrm{L}$ each of forward and reverse primers (Table $S 2,10 \mu \mathrm{M}$ ), and $8 \mu \mathrm{L}$ MilliQ water. Reactions were run using a PCR thermal cycler (Applied Biosystem, Thermo Fisher Scientific) as follows: 30 cycles of $98^{\circ} \mathrm{C}$ for $10 \mathrm{~s}, 58-62^{\circ} \mathrm{C}$ for $30 \mathrm{~s}$ followed by $72^{\circ} \mathrm{C}$ for $1 \mathrm{~min} / \mathrm{kb}$. PCR products were then run on a SYBR safe stained $1-2 \%$ agarose gel at $100 \mathrm{~V}$.

qPCR experiments were performed using SYBR Green qPCR Supermix-UDG with ROX (Invitrogen) as per the manufacturer's instructions. Briefly, $2 \mu \mathrm{L}$ cDNA (100-150 ng/ $\mu \mathrm{L})$ was added to $5 \mu \mathrm{L}$ SYBR Green qPCR Supermix, $0.2 \mu \mathrm{L}$ each of the forward and reverse primers (Table $S 2,10 \mu \mathrm{M}$ ) and $2.6 \mu \mathrm{L}$ MilliQ water. Samples were added to a 384 -well plate and reactions run using the following conditions: $50^{\circ} \mathrm{C}$ for $2 \mathrm{~min}, 95^{\circ} \mathrm{C}$ for $10 \mathrm{~min}$ then 40 cycles of $95^{\circ} \mathrm{C}$ for $15 \mathrm{~s}$ and $60^{\circ} \mathrm{C}$ for $1 \mathrm{~min}$ followed by a melt curve analysis. Each condition was performed in triplicate and $\beta$-actin was used as the housekeeping gene. The expression level of the target gene was plotted as the averaged mean CT value \pm SEM of the three technical replicates.

\section{Flow cytometry}

Cells were detached with TrypLE or accutase to avoid cleaving cell surface markers. Equine PBMCs were used as the positive control for negatively expressed MSC cell surface marker proteins. For each experimental condition, 500,000 cells were washed in FACS buffer (1\% FBS in PBS), resuspended in 100 $\mu \mathrm{L}$ fresh FACS buffer containing $5 \mu \mathrm{L}$ primary antibody and incubated in the dark for 30 min on ice. Cells were washed in FACS buffer, and for unconjugated primary antibodies, cells were incubated with $1 \mu \mathrm{L}$ secondary antibody in $1 \mathrm{~mL}$ FACS buffer for a further $30 \mathrm{~min}$ on ice. Cells were washed a final time, resuspended in $1 \mathrm{~mL}$ buffer, and expression of cell surface markers immediately examined using a fixed voltage CyFlow Cube8 flow cytometer (Sysmex, Japan). The forward and side scatter parameters were used to determine and gate cell populations. At least 10,000 events were acquired, with the no primary antibody control used to discriminate positive from negative staining. 


\section{Tri-lineage differentiation assays}

Tri-lineage differentiation was examined for the SF, J and FM cell lines. Where possible, differentiation into adipogenic, osteogenic, and chrondrogenic lineages were examined at an early, middle, and late passage of the cell line growth potential. It was attempted to match experimental passages across differentiation assays and is noted where this was not possible. For all differentiation assays, two wells or cell pellets were subjected to differentiation medium while a third was used as an undifferentiated control. Differentiation was examined using an It-UEclipse inverted microscope (Nikon) with 10x, 20x or 40x non-confocal objective lens.

\section{Adipogenic differentiation}

Cells were plated at a density of 500,000 cells per well in a 6-well plate. The following day, growth media was removed and replaced with $2 \mathrm{~mL}$ complete MesenCult Adipogenic differentiation medium (Stemcell Technologies, Canada). Cells were incubated at $37^{\circ} \mathrm{C}$ with $5 \% \mathrm{CO}_{2}$ for 14 or 21 days with the media changed every 3 days. On days 14 and 21, cells were washed in PBS and fixed with 4\% PFA for 30 min. Cells were washed and incubated in $60 \%$ isopropanol for $5 \mathrm{~min}$ before replacement with Oil Red 0 working solution for $5 \mathrm{~min}$. The cells were then washed with water, counterstained with Hematoxylin and imaged for lipid formation.

\section{Osteogenic differentiation}

Cells were plated at a density of 1,000 cells per well in a 6-well plate. The day after plating, growth media was replaced with Osteogenic Stimulatory medium containing 10\% FBS, $0.01 \mu \mathrm{M}$ dexamethasone, 10 $\mathrm{mM} \beta$-Glycerophosphate, $50 \mu \mathrm{M}$ ascorbic acid, and $1 \%$ anti-anti. Plates were incubated at $37^{\circ} \mathrm{C}$ with $5 \%$ $\mathrm{CO}_{2}$ for 14,21 , or 24 days with the media being changed every 3 days. On days 14,21 , and 24 , cells were washed in PBS and fixed with 4\% PFA for 30 minutes. Following fixation, cells were washed and incubated in the dark with Alizarin Red S staining solution for 45 minutes. The cells were then washed with water and imaged for calcium deposits.

\section{Chondrogenic differentiation}

Cell pellets were formed by resuspending 500,000 cells in $0.5 \mathrm{~mL}$ growth media and transferring the suspension to a $15 \mathrm{~mL}$ centrifuge tube. The tubes were spun at $300 \times \mathrm{g}$ for 5-10 min at RT. The caps were loosened, and pellets grown at $37^{\circ} \mathrm{C}$ with $5 \% \mathrm{CO}_{2}$ for 3 days. On day $3,0.5 \mathrm{~mL}$ complete MesenCultACF differentiation medium (Stemcell Technologies, Canada) was added to give a final volume of $1 \mathrm{~mL}$. The media was replaced with $0.5 \mathrm{~mL}$ fresh differentiation medium every 3 days until day 21 . On day 21 , cell pellets were washed in PBS, fixed in 4\% PFA for $30 \mathrm{~min}$, and stored in 70\% ethanol for paraffin embedding and sectioning. Sections $(6 \mu \mathrm{m})$ were deparafinised, rehydrated then incubated for $3 \mathrm{~min}$ in $3 \%$ acetic acid and washed in water. Alcian Blue solution was added to each section and incubated for 30 min in a humidified chamber. Sections were washed and cover slipped before being imaged.

\section{Culturing cells in bioreactors}


Three bioreactors were chosen to test high-density culturing of cells; one CELLine ${ }^{T M}$ AD 1000 flask for adherent cells and two FiberCell ${ }^{\mathrm{TM}}$ hollow fiber bioreactors using cartridges manufactured with different fibres referred as 2025D and 2025G. The 2025D fibres were modified by coating them with fibronectin to improve adhesion. The bioreactors were operated following the manufacturers' instructions. Both FiberCell $^{\text {TM }}$ bioreactors went through a pre-culturing wash step that included circulating PBS for $24 \mathrm{hrs,}$ followed by DMEM/F12 and then DMEM/F12 with 10\% FBS for 24 hrs each. The bioreactor 2025D was coated with fibronectin at $50 \mu \mathrm{g} / \mathrm{mL}$ at $37^{\circ} \mathrm{C}$ for $1 \mathrm{hr}$ prior to circulating DMEM/F12 with $10 \% \mathrm{FBS}$. Each bioreactor was seeded with $30 \times 10^{6}$ viable MSCs in DMEM/F12 containing $10 \%$ FBS and grown for three weeks before gradually removing the FBS and replacing it with the serum replacement CDM-HD (Fig. 6A). The culturing scheme and medium composition are indicated in Figure S1.

\section{Hoechst staining}

At the end of the culture period, cells in the CELLine ${ }^{\text {TM }}$ flask were stained with hoechst (1:1000 dilution) for $10 \mathrm{~min}$ at $37^{\circ} \mathrm{C}$. Excess stain was washed off and the cells imaged using a fluorescent microscope.

\section{Scanning electron microscopy}

All bioreactors were washed with PBS briefly and fixed with McDowell and Trump's Fixative (4\% formaldehyde, $1 \%$ glutaraldehyde, $0.1 \mathrm{M}$ phosphate buffer, $\mathrm{pH} 7.2$ ) for $30 \mathrm{~min}$. Fixed samples were washed with PBS twice, then dehydrated with 35\%, 50\%, 70\%, 90\% (2x 10 min each) and 100\% ethanol (3x $15 \mathrm{~min}$ ). The Fibercell ${ }^{\mathrm{TM}}$ bioreactors were fixed and dehydrated while the hollow fiber bundles were still intact inside the plastic shell. The cartridge units were disconnected from the medium reservoir and the fixation and dehydration reagents were injected both inside the fibers and through the side port to the cell chamber using a syringe. The CELLin $\mathrm{e}^{\mathrm{TM}}$ AD 1000 was disassembled and cut into pieces suitable for fixation and dehydration. After the dehydration step, specimens from all bioreactors were air dried and sputter coated with $10 \mathrm{~nm}$ gold (Q150R S, Quorum) then imaged using a JCM-6000 benchtop scanning electron microscope (SEM) (JEOL) at $15 \mathrm{kV}$.

\section{Collection and characterisation of EVs}

Initially, to collect EVs, the MSCs were transferred to T175 flasks. The MSCs were grown to $60 \%-70 \%$ confluence before changing the medium to DMEM/F12 without serum, supplemented with $1 \mathrm{x}$ nonessential amino acids (NEAA, Thermo Fisher Scientific) and the culture continued for 3 days. The medium was then collected and centrifuged at $2000 \times g$ at $4^{\circ} \mathrm{C}$ for 20 min to remove any cells and large debris. EVs were harvested from the supernatant by centrifuging at $100,000 \times g$ for $1 \mathrm{hr}$ at $4^{\circ} \mathrm{C}$ using a Sorvall WX100 + ultracentrifuge (Thermo Fisher Scientific) and resuspended in PBS.

Medium harvested from FiberCell ${ }^{T M}$ bioreactors were processed in the same fashion. Collected EVs were diluted in PBS to allow detection of $1 \times 10^{7}$ to $1 \times 10^{9}$ particles $/ \mathrm{mL}$ using a Nanosight NS300. Samples were measured using a flow rate of 50 and five 30 s videos were taken and averaged for each reading. Duplicate readings were made for each sample and the same settings were used for all samples. 
Negative staining transmission electron microscopy (TEM) of equine MSC EVs was conducted by adsorption onto Formvar-coated copper grids (Electron Microscopy Sciences) for 10 minutes. Excess liquid was removed with filter paper (Whatman) and the copper grid was transferred to $20 \mu \mathrm{L}$ of $2 \%$ filtered uranyl acetate for 2 min. Excess liquid was again removed with filter paper and the grid left to dry under a lamp for $10 \mathrm{~min}$. Grids were visualized on Tecnai G2 Spirit TWIN (FEI, Hillsboro, OR, USA) TEM at $120 \mathrm{kV}$ accelerating voltage. Images were captured using a Morada digital camera (SIS GmbH, Munster, Germany).

\section{Declarations}

\section{Acknowledgements}

The authors would like to thank the Hub for Extracellular Vesicle Investigations at the University of Auckland for their continued support.

\section{Author Contributions}

Z.T., W.H., T.D., K.S., M.K., Y.G., and C.H. performed experiments and analyses; Z.T., W.H., C.H., and L.C. wrote the original draft; all authors contributed to the experimental design and contributed to the interpretation and discussion of results. The authors have read and approved the final manuscript.

\section{Competing Interests}

The authors have no competing interests to disclose.

\section{Data Availability}

The datasets used during this study are available from the corresponding author upon reasonable request.

\section{References}

1. Viswanathan, S. et al. Mesenchymal stem versus stromal cells: International Society for Cell \& Gene Therapy (ISCT(R)) Mesenchymal Stromal Cell committee position statement on nomenclature. Cytotherapy 21, 1019-1024, doi:10.1016/j.jcyt.2019.08.002 (2019).

2. Dominici, M. et al. Minimal criteria for defining multipotent mesenchymal stromal cells. The International Society for Cellular Therapy position statement. Cytotherapy 8, 315-317, doi:10.1080/14653240600855905 (2006).

3. Mocchi, M. et al. Veterinary Regenerative Medicine for Musculoskeletal Disorders: Can Mesenchymal Stem/Stromal Cells and Their Secretome Be the New Frontier? Cells 9, 1453, doi:10.3390/cells9061453 (2020).

4. Dabrowska, S., Andrzejewska, A., Janowski, M. \& Lukomska, B. Immunomodulatory and Regenerative Effects of Mesenchymal Stem Cells and Extracellular Vesicles: Therapeutic Outlook for Inflammatory 
and Degenerative Diseases. Frontiers in Immunology 11, 3809 (2021).

5. van Niel, G., D'Angelo, G. \& Raposo, G. Shedding light on the cell biology of extracellular vesicles. Nature Reviews Molecular Cell Biology 19, 213-228, doi:10.1038/nrm.2017.125 (2018).

6. Capomaccio, S. et al. Equine Adipose-Derived Mesenchymal Stromal Cells Release Extracellular Vesicles Enclosing Different Subsets of Small RNAs. Stem Cells Int 2019, 4957806-4957806, doi:10.1155/2019/4957806 (2019).

7. Harrell, C. R. et al. Molecular Mechanisms Responsible for Therapeutic Potential of Mesenchymal Stem Cell-Derived Secretome. Cells 8, doi:10.3390/cells8050467 (2019).

8. Mokarizadeh, A. et al. Microvesicles derived from mesenchymal stem cells: Potent organelles for induction of tolerogenic signaling. Immunology Letters 147, 47-54, doi:https://doi.org/10.1016/j.imlet.2012.06.001 (2012).

9. Lehrich, B. M., Liang, Y. \& Fiandaca, M. S. Foetal bovine serum influence on in vitro extracellular vesicle analyses. J Extracell Vesicles 10, e12061-e12061, doi:10.1002/jev2.12061 (2021).

10. Dewar, V., Voet, P., Denamur, F. \& Smal, J. Industrial Implementation of in Vitro Production of Monoclonal Antibodies. ILAR Journal 46, 307-313, doi:10.1093/ilar.46.3.307 (2005).

11. Artuyants, A. et al. Production of Extracellular Vesicles Using a CELLine Adherent Bioreactor Flask. Methods Mol Biol, doi:10.1007/7651_2021_413 (2021).

12. Hisey, C. L., Tomek, P., Nursalim, Y. N. S., Chamley, L. W. \& Leung, E. Towards establishing extracellular vesicle-associated RNAs as biomarkers for HER2 + breast cancer. F1000Res 9, 1362, doi:10.12688/f1000research.27393.2 (2020).

13. Watson, D. C. et al. Efficient production and enhanced tumor delivery of engineered extracellular vesicles. Biomaterials 105, 195-205, doi:10.1016/j.biomaterials.2016.07.003 (2016).

14. Watson, D. C. et al. Scalable, cGMP-compatible purification of extracellular vesicles carrying bioactive human heterodimeric IL-15/lactadherin complexes. J Extracell Vesicles 7, 1442088, doi:10.1080/20013078.2018.1442088 (2018).

15. Guerreiro, E. M. et al. Efficient extracellular vesicle isolation by combining cell media modifications, ultrafiltration, and size-exclusion chromatography. PLoS One 13, e0204276, doi:10.1371/journal.pone.0204276 (2018).

16. Mitchell, J. P., Court, J., Mason, M. D., Tabi, Z. \& Clayton, A. Increased exosome production from tumour cell cultures using the Integra CELLine Culture System. J Immunol Methods 335, 98-105, doi:10.1016/j.jim.2008.03.001 (2008).

17. Lv, F.-J., Tuan, R. S., Cheung, K. M. C. \& Leung, V. Y. L. Concise Review: The Surface Markers and Identity of Human Mesenchymal Stem Cells. STEM CELLS 32, 1408-1419, doi:https://doi.org/10.1002/stem.1681 (2014).

18. Stanko, P., Kaiserova, K., Altanerova, V. \& Altaner, C. Comparison of human mesenchymal stem cells derived from dental pulp, bone marrow, adipose tissue, and umbilical cord tissue by gene expression. Biomedical papers 158, 373-377, doi:10.5507/bp.2013.078 (2014). 
19. Elahi, K. C. et al. Human Mesenchymal Stromal Cells from Different Sources Diverge in Their Expression of Cell Surface Proteins and Display Distinct Differentiation Patterns. Stem Cells Int 2016, 5646384, doi:10.1155/2016/5646384 (2016).

20. Mutlu, L., Hufnagel, D. \& Taylor, H. S. The endometrium as a source of mesenchymal stem cells for regenerative medicine. Biol Reprod 92, 138-138, doi:10.1095/biolreprod.114.126771 (2015).

21. Zhou, S. et al. Age-related intrinsic changes in human bone-marrow-derived mesenchymal stem cells and their differentiation to osteoblasts. Aging Cell 7, 335-343, doi:10.1111/j.14749726.2008.00377.x (2008).

22. Barberini, D. J. et al. Equine mesenchymal stem cells from bone marrow, adipose tissue and umbilical cord: immunophenotypic characterization and differentiation potential. Stem cell research \& therapy 5, 25-25, doi:10.1186/scrt414 (2014).

23. Dominici, M. et al. Minimal criteria for defining multipotent mesenchymal stromal cells. The International Society for Cellular Therapy position statement. Cytotherapy 8, 315-317, doi:10.1080/14653240600855905 (2006).

24. De Schauwer, C., Meyer, E., Van de Walle, G. R. \& Van Soom, A. Markers of stemness in equine mesenchymal stem cells: a plea for uniformity. Theriogenology $75,1431-1443$, doi:10.1016/j.theriogenology.2010.11.008 (2011).

25. Harman, R. M. et al. Single-cell RNA sequencing of equine mesenchymal stromal cells from primary donor-matched tissue sources reveals functional heterogeneity in immune modulation and cell motility. Stem Cell Res Ther 11, 524, doi:10.1186/s13287-020-02043-5 (2020).

26. De Schauwer, C. et al. In search for cross-reactivity to immunophenotype equine mesenchymal stromal cells by multicolor flow cytometry. Cytometry A 81, 312-323, doi:10.1002/cyto.a.22026 (2012).

27. Carrade, D. D. et al. Clinicopathologic findings following intra-articular injection of autologous and allogeneic placentally derived equine mesenchymal stem cells in horses. Cytotherapy $13,419-430$, doi:10.3109/14653249.2010.536213 (2011).

28. Ulrich, C. et al. Human Placenta-Derived CD146-Positive Mesenchymal Stromal Cells Display a Distinct Osteogenic Differentiation Potential. Stem Cells and Development 24, 1558-1569, doi:10.1089/scd.2014.0465 (2015).

29. Pilz, G.-A. et al. Human Term Placenta-Derived Mesenchymal Stromal Cells Are Less Prone to Osteogenic Differentiation Than Bone Marrow-Derived Mesenchymal Stromal Cells. Stem cells and development 20, 635-646, doi:10.1089/scd.2010.0308 (2010).

30. MacDonald, E. S. \& Barrett, J. G. The Potential of Mesenchymal Stem Cells to Treat Systemic Inflammation in Horses. Frontiers in Veterinary Science 6, 507 (2020).

31. Smith, R. K. W., Garvican, E. R. \& Fortier, L. A. The current 'state of play' of regenerative medicine in horses: what the horse can tell the human. Regenerative Medicine 9, 673-685, doi:10.2217/rme.14.42 (2014). 
32. Lechanteur, C. et al. Clinical-scale expansion of mesenchymal stromal cells: a large banking experience. Journal of Translational Medicine 14, 145, doi:10.1186/s12967-016-0892-y (2016).

33. Arevalo-Turrubiarte, M., Baratta, M., Ponti, G., Chiaradia, E. \& Martignani, E. Extracellular vesicles from equine mesenchymal stem cells decrease inflammation markers in chondrocytes in vitro. Equine Vet J, doi:10.1111/evj.13537 (2021).

34. Mocchi, M. et al. Veterinary Regenerative Medicine for Musculoskeletal Disorders: Can Mesenchymal Stem/Stromal Cells and Their Secretome Be the New Frontier? Cells-Base/ 9 , doi:10.3390/cells9061453 (2020).

35. Otsuru, S. et al. Extracellular vesicles released from mesenchymal stromal cells stimulate bone growth in osteogenesis imperfecta. Cytotherapy 20, 62-73, doi:10.1016/j.jcyt.2017.09.012 (2018).

36. Iso, Y. et al. Multipotent human stromal cells improve cardiac function after myocardial infarction in mice without long-term engraftment. Biochem Biophys Res Commun 354, 700-706, doi:10.1016/j.bbrc.2007.01.045 (2007).

37. Noiseux, N. et al. Mesenchymal stem cells overexpressing Akt dramatically repair infarcted myocardium and improve cardiac function despite infrequent cellular fusion or differentiation. Mol Ther 14, 840-850, doi:10.1016/j.ymthe.2006.05.016 (2006).

38. Hotham, W. E., Thompson, C., Szu-Ting, L. \& Henson, F. M. D. The anti-inflammatory effects of equine bone marrow stem cell-derived extracellular vesicles on autologous chondrocytes. Vet Rec Open 8, e22-e22, doi:10.1002/vro2.22 (2021).

39. Lange-Consiglio, A. et al. Equine Amniotic Microvesicles and Their Anti-Inflammatory Potential in a Tenocyte Model In Vitro. Stem cells and development 25, doi:10.1089/scd.2015.0348 (2016).

40. D'Arrigo, D. et al. Secretome and Extracellular Vesicles as New Biological Therapies for Knee Osteoarthritis: A Systematic Review. Journal of Clinical Medicine 8, doi:10.3390/jcm8111867 (2019).

41. Ferris, R. A., Frisbie, D. D. \& McCue, P. M. Use of mesenchymal stem cells or autologous conditioned serum to modulate the inflammatory response to spermatozoa in mares. Theriogenology $82,36-42$, doi:10.1016/j.theriogenology.2014.02.015 (2014).

42. Malard, P. F. et al. Intraovarian injection of mesenchymal stem cells improves oocyte yield and in vitro embryo production in a bovine model of fertility loss. Sci Rep 10, 8018, doi:10.1038/s41598020-64810-x (2020).

43. Al Naem, M., Bourebaba, L., Kucharczyk, K., Rocken, M. \& Marycz, K. Therapeutic mesenchymal stromal stem cells: Isolation, characterization and role in equine regenerative medicine and metabolic disorders. Stem Cell Rev Rep 16, 301-322, doi:10.1007/s12015-019-09932-0 (2020).

44. Das, R. et al. Preparing for cell culture scale-out: establishing parity of bioreactor- and flask-expanded mesenchymal stromal cell cultures. J Transl Med 17, 241, doi:10.1186/s12967-019-1989-x (2019).

45. Palviainen, M. et al. Metabolic signature of extracellular vesicles depends on the cell culture conditions. J Extracell Vesicles 8, 1596669-1596669, doi:10.1080/20013078.2019.1596669 (2019).

46. de Mestre, A. M. et al. Functions of ectopically transplanted invasive horse trophoblast. Reproduction 141, 849-856, doi:10.1530/REP-10-0462 (2011). 
Figures

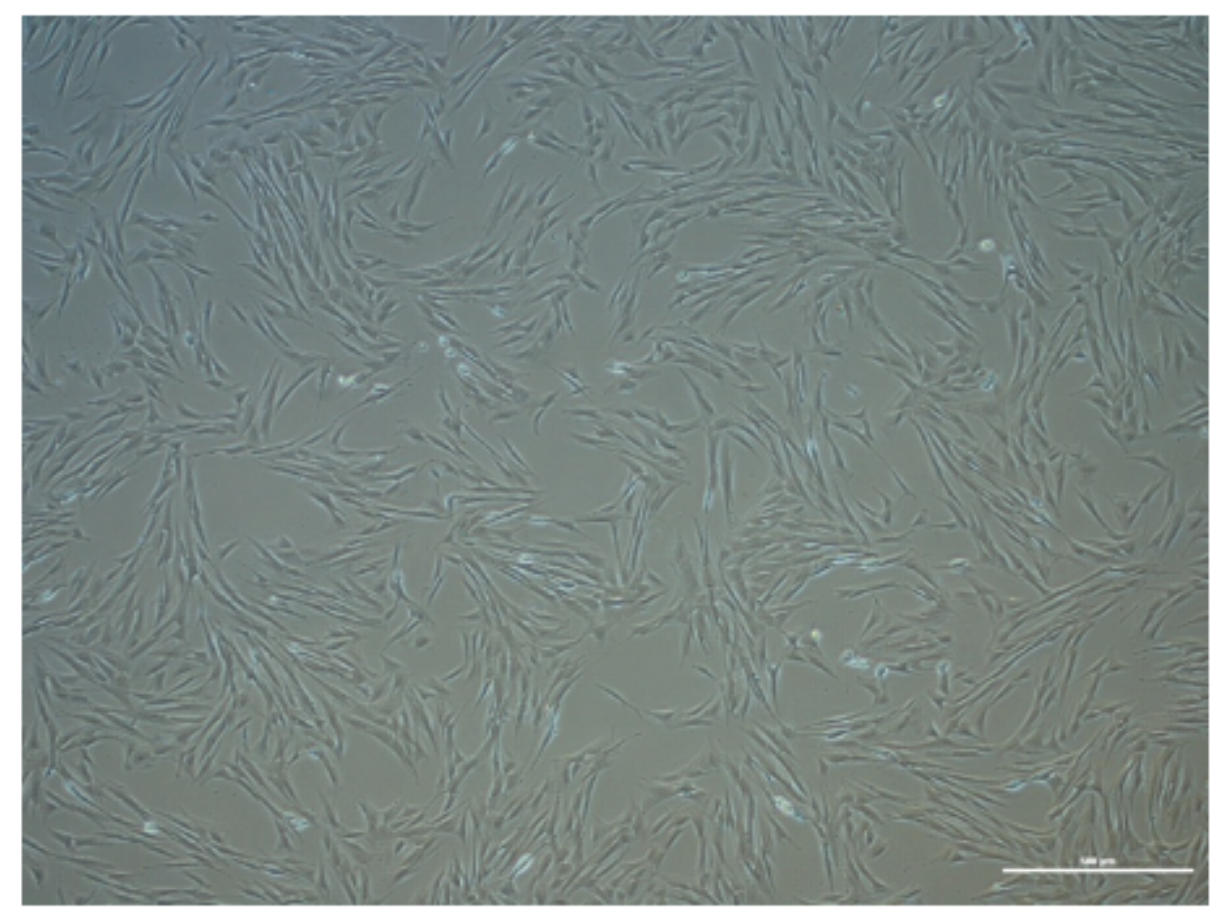

Figure 1

Phase-contrast photomicrograph demonstrating the morphology of the MSC-like cells cultured from equine pre-implantation embryos. Image taken using a 4x non-confocal objective. Scale bar, $500 \mu \mathrm{m}$. 
A)
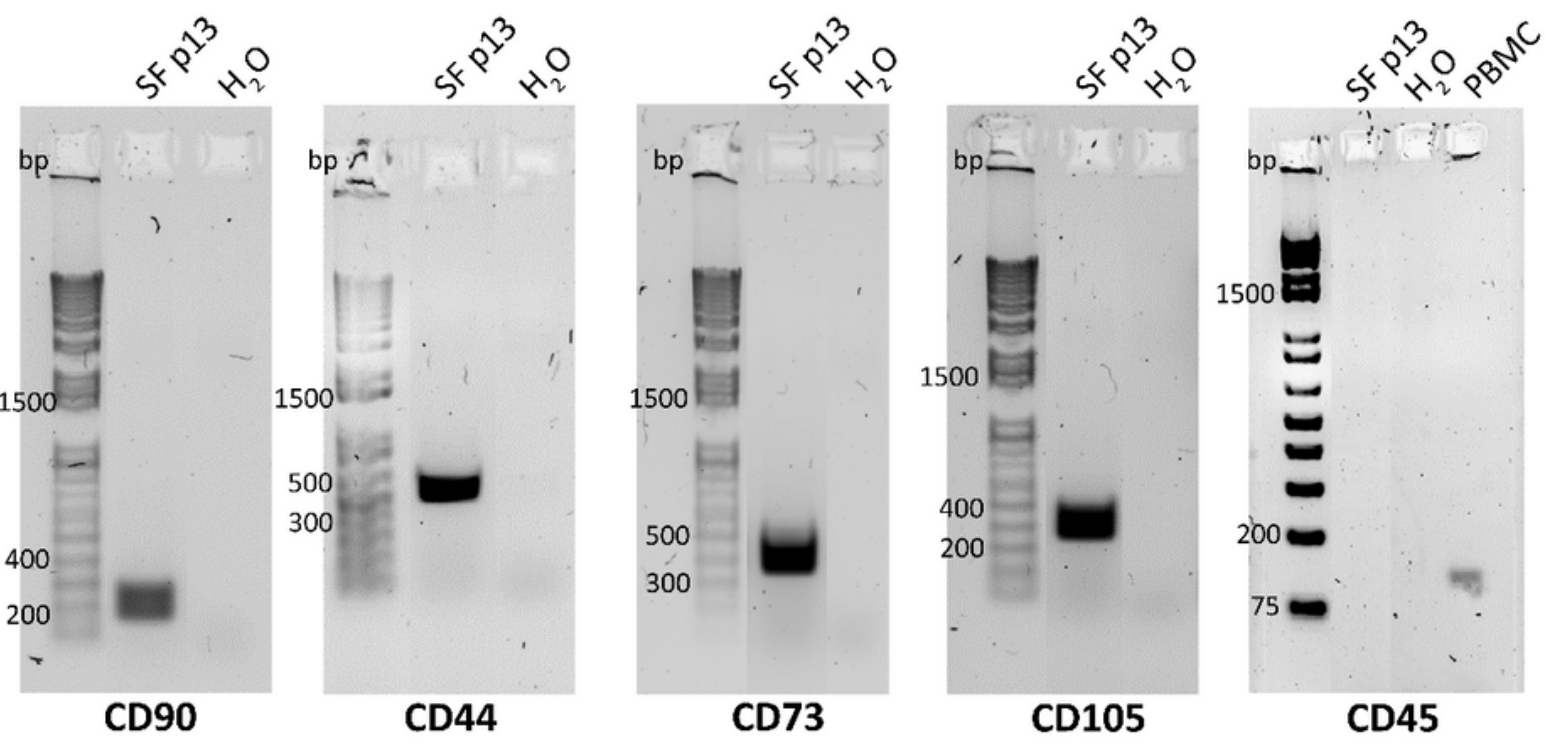

B)

\begin{tabular}{|c|c|c|c|c|c|c|c|c|c|}
\hline & & $\begin{array}{l}\text { FM } \\
\text { p9/p10n }\end{array}$ & $\begin{array}{l}\text { FM } \\
\text { p16 }\end{array}$ & $\begin{array}{l}\text { SF } \\
\text { p8 }\end{array}$ & $\begin{array}{l}\text { SF } \\
\mathrm{p} 14 / \mathrm{p} 13^{\wedge}\end{array}$ & $\begin{array}{l}\text { SF } \\
\text { p26 }\end{array}$ & $\begin{array}{l}\mathrm{p} 7 / \mathrm{p8}{ }^{\wedge} \\
\end{array}$ & $\begin{array}{l} \\
\text { p13 }\end{array}$ & $\begin{array}{l}\text { J } \\
\text { p18 }\end{array}$ \\
\hline \multirow{5}{*}{$\begin{array}{l}\text { Positive } \\
\text { markers }\end{array}$} & $\begin{array}{l}\text { CD90 } \\
\text { (PCR/Flow) }\end{array}$ & $+/+$ & $+/+$ & $+/+$ & $+/+$ & $+/ X$ & $+/+$ & $+/+$ & $+/+$ \\
\hline & $\begin{array}{l}\text { CD105 } \\
\text { (PCR) }\end{array}$ & + & + & + & + & + & + & + & - \\
\hline & $\begin{array}{l}\text { CD73 } \\
\text { (PCR) }\end{array}$ & + & + & + & + & + & + & + & + \\
\hline & $\begin{array}{l}\text { CD44 } \\
\text { (PCR/Flow) }\end{array}$ & $+/+$ & $+/+$ & $+/+$ & $+/+$ & $+/ X$ & $+/+$ & $+/+$ & $+/+$ \\
\hline & $\begin{array}{l}\text { MHC-I } \\
\text { (Flow) }\end{array}$ & + & + & + & + & $x$ & + & + & + \\
\hline \multirow{5}{*}{$\begin{array}{l}\text { Negative } \\
\text { markers }\end{array}$} & $\begin{array}{l}\text { CD45 } \\
\text { (PCR/Flow) }\end{array}$ & $-/+$ & $-/+$ & $-/-$ & $-/+$ & $-/ x$ & $-/+$ & $-/+$ & $-/+$ \\
\hline & $\begin{array}{l}\text { CD34 } \\
\text { (qPCR) }\end{array}$ & + & - & ++ & + & - & ++ & ++ & + \\
\hline & $\begin{array}{l}\text { CD31 } \\
\text { (qPCR) }\end{array}$ & - & - & + & + & - & - & - & - \\
\hline & $\begin{array}{l}\text { CD14 } \\
\text { (Flow) }\end{array}$ & $x$ & - & + & - & $x$ & - & $x$ & - \\
\hline & $\begin{array}{l}\text { MHC-II } \\
\text { (Flow) }\end{array}$ & - & - & - & - & $x$ & - & - & - \\
\hline
\end{tabular}

\section{Figure 2}

Characterisation of equine MSC-like cell surface marker protein expression. A) RT-PCR detected expression of CD90, CD44, CD73, CD105 and lack of CD45 expression in SF p14. Gel lanes are cropped from original gels for presentation and are representative of the original gel (Figure S3). All markers were run on a $1 \%$ agarose gel, except CD 45 which was run on a $2 \%$ gel. B) Summary table of cell surface marker expression for SF, FM and $\mathrm{J}$ cell lines at multiple passages by RT-PCR, flow cytometry and qPCR. 
Where multiple methods were used, the expression by RT-PCR is indicated first followed by flow cytometry (Flow). For RT-PCR and flow cytometry experiments: + = marker expressed, - = marked not expressed. For qPCR experiments: $+=$ low gene expression, $++=$ moderate gene expression and $+++=$ high gene expression. ${ }^{\wedge}=$ passage used in flow cytometry experiments. ${ }^{*}$ PBMCs were used as positive control. $\mathrm{X}=$ not tested.

\section{Control}

\section{A)}

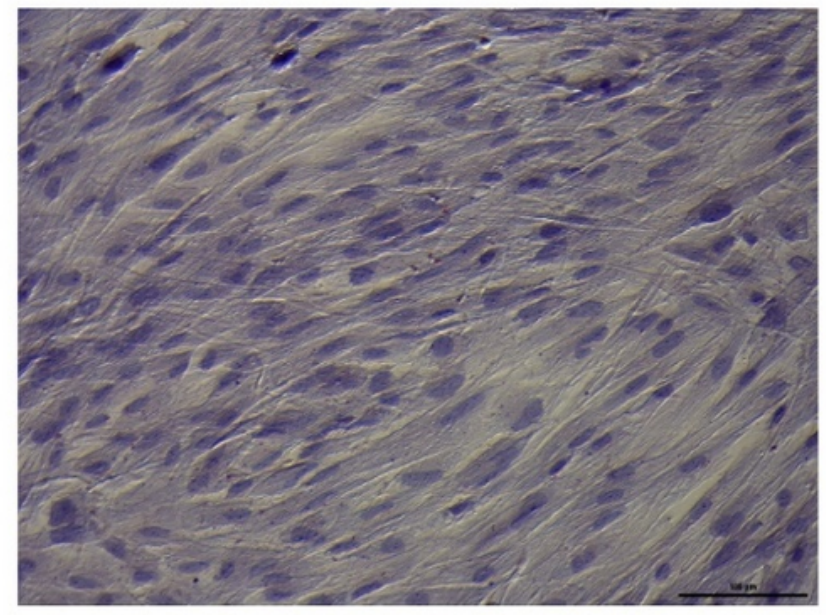

B)

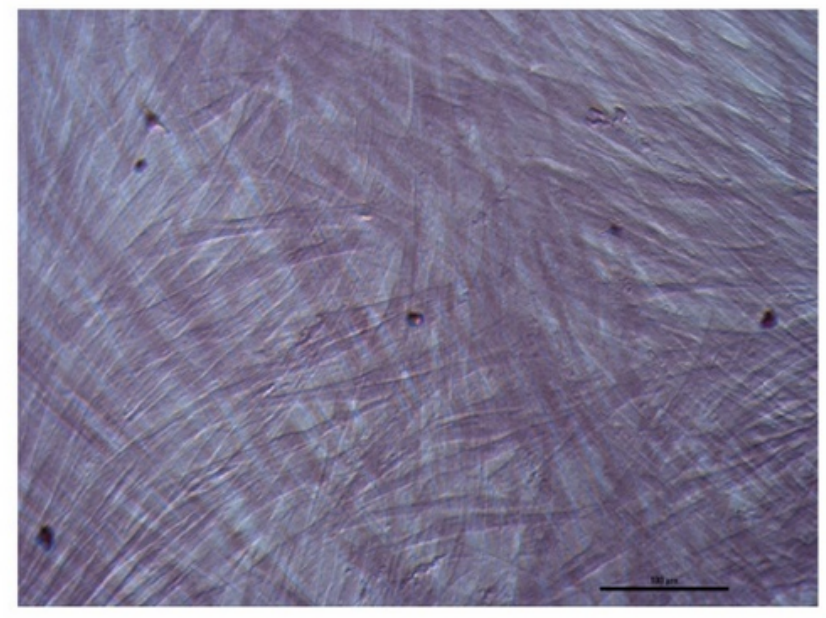

C)

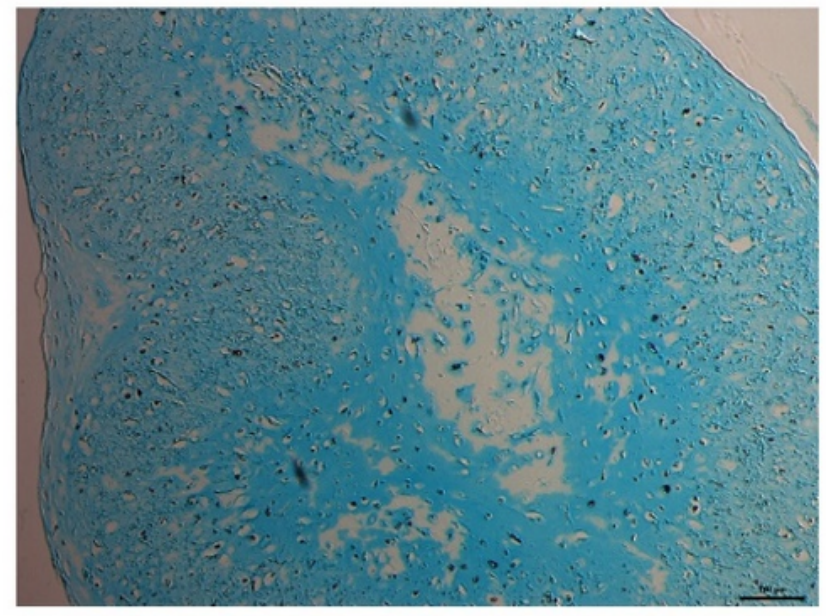

\section{Differentiated}
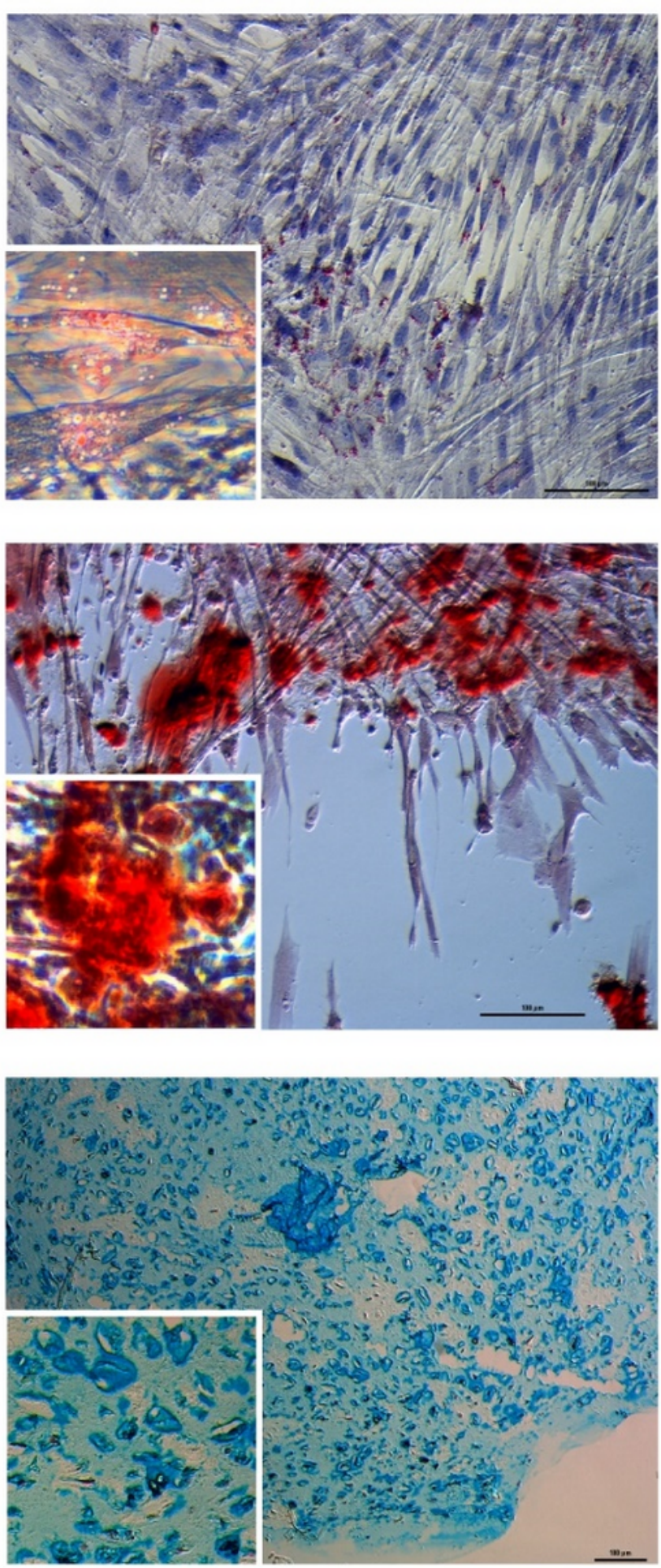

Figure 3 
Tri-lineage differentiation of SF equine MSC-like cells. Representative images of control and differentiated cells following 21 days in differentiation conditions A) Adipogenic differentiation, B) Osteogenic differentiation, and $C$ ) Chondrogenic differentiation. Inset images are regions shown at higher magnification. Images were taken using a 20x (A, B) or $10 \times$ (C) objective. Scale bar, $100 \mu \mathrm{m}$.

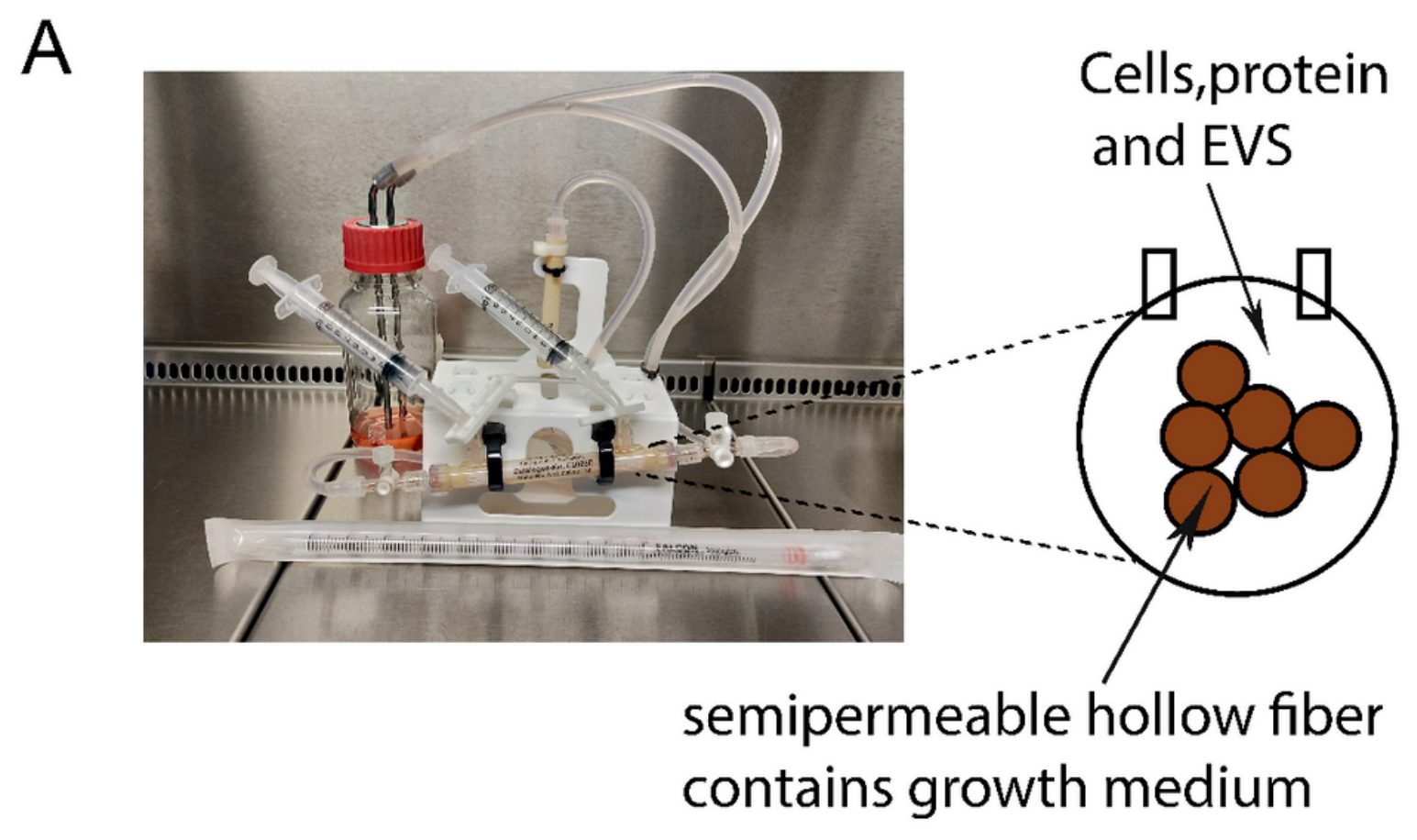

B

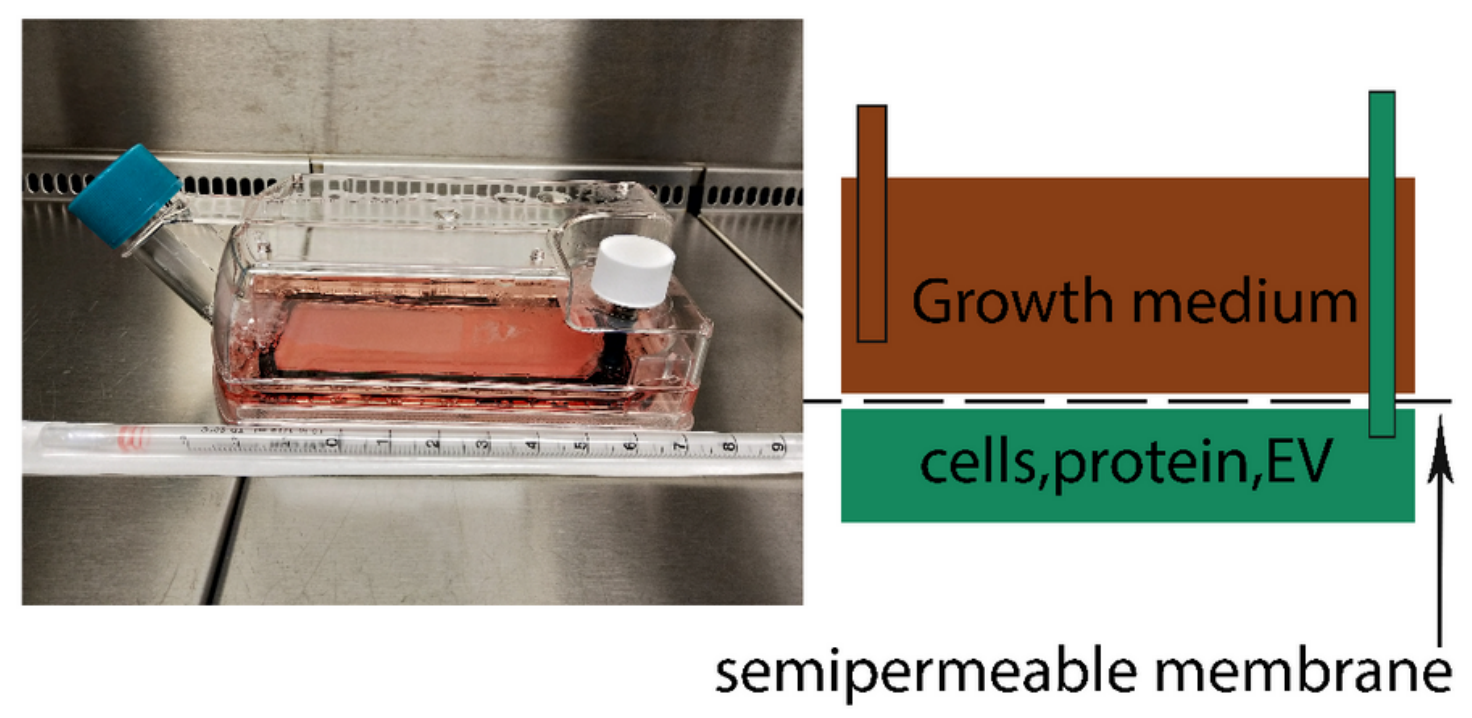

Figure 4

The A) Fibercell ${ }^{T M}$ and B) CELLine ${ }^{T M}$ AD 1000 flask bioreactor systems. A) The FiberCell ${ }^{T M}$ bioreactor includes multiple hollow fibers enclosed in a plastic shell. Cells grow on the outside of the fibers while medium is pumped through the fibers. The hollow fiber are porous with a molecular weight cut-off of 20 
kDa that allows nutrient/waste exchange. B) The CELLine ${ }^{\mathrm{TM}}$ system employs a semipermeable membrane with a molecular weight cut-off of $10 \mathrm{KDa}$ that separates the flask into an upper medium chamber with a capacity of $1 \mathrm{~L}$ and a small $15 \mathrm{~mL}$ chamber with a fibrous mesh growth surface to facilitate cell adhesion.

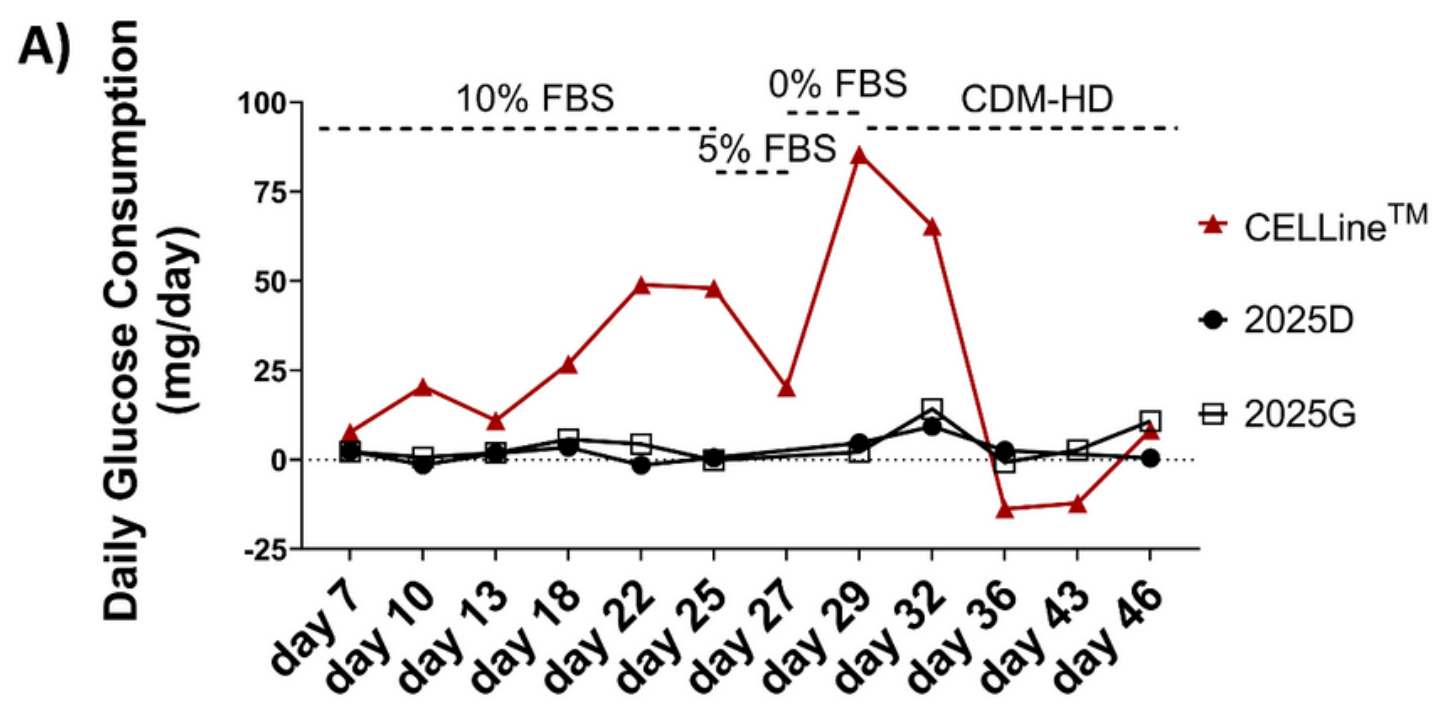

B)

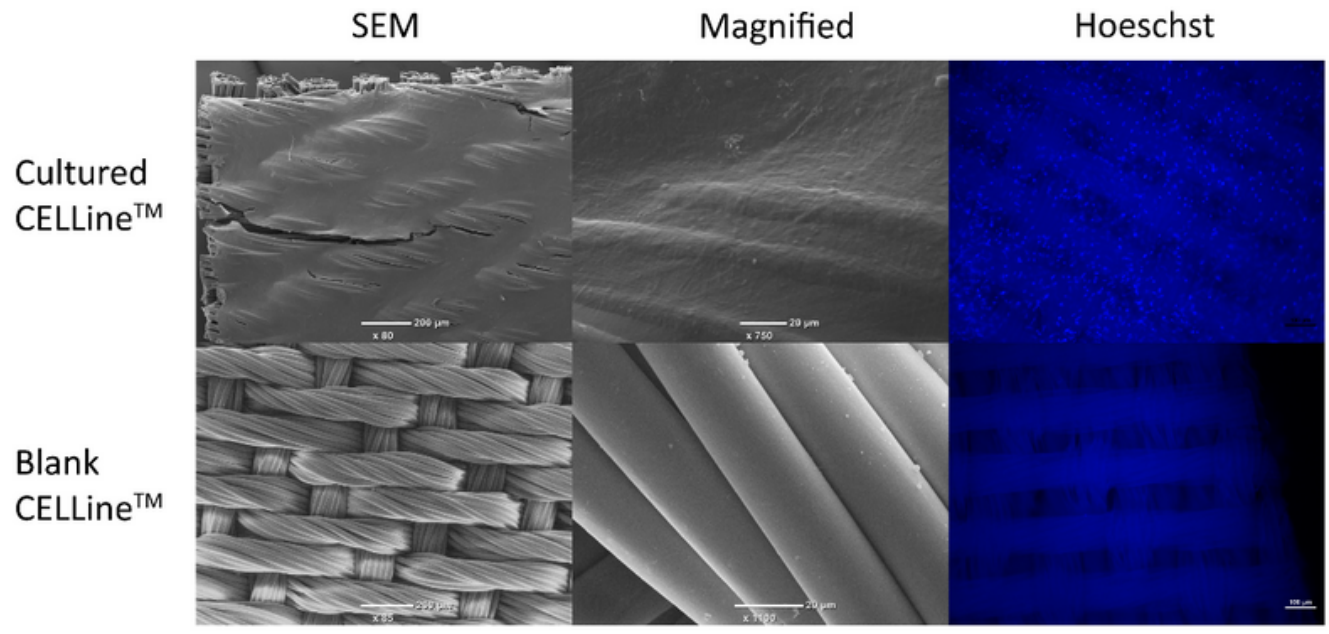

C)

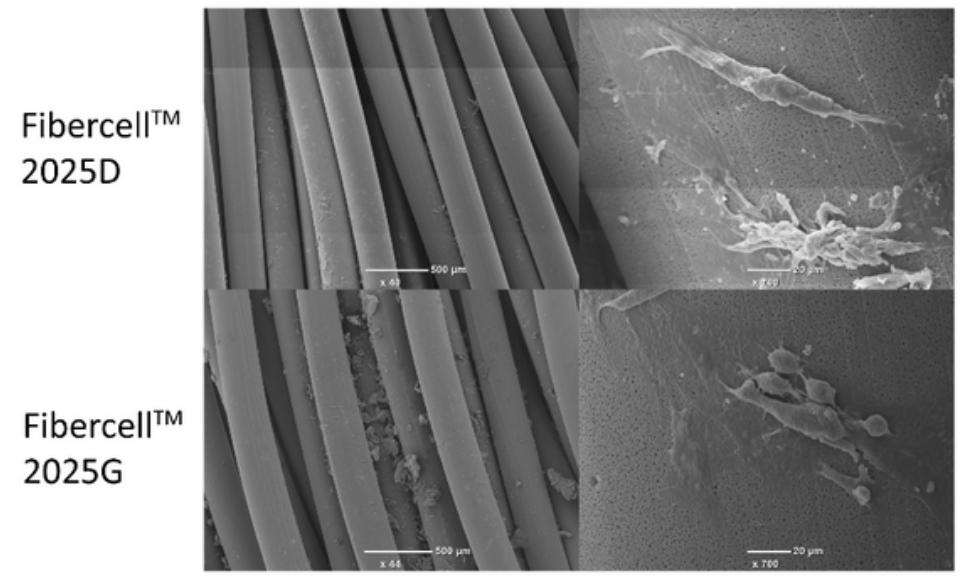

Figure 5 
Equine MSC proliferation and growth pattern in bioreactors. A) Daily glucose consumption rate of MSC cells. SEM images showing the different morphology and growth pattern of MSCs in the B) CELLine and C) Fibercell bioreactors. CELLine ${ }^{T M}$ flask was also stained with Hoechst to reveal the nuclei. The scale bars for $\mathrm{B}$ ) and $\mathrm{C}$ ) are indicated on each image.

A)

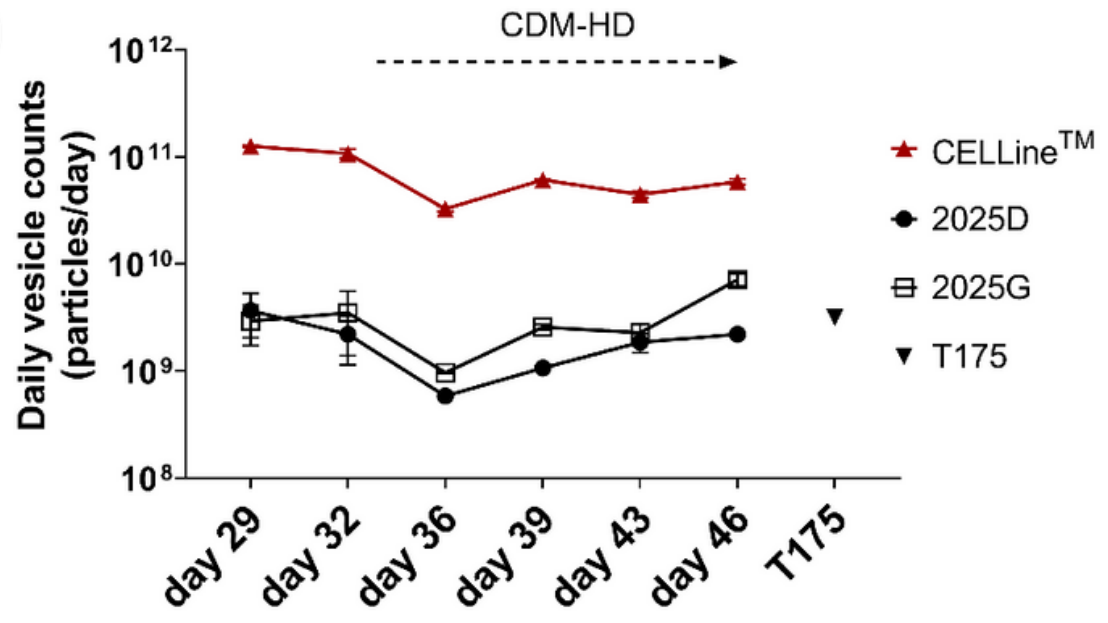

C)

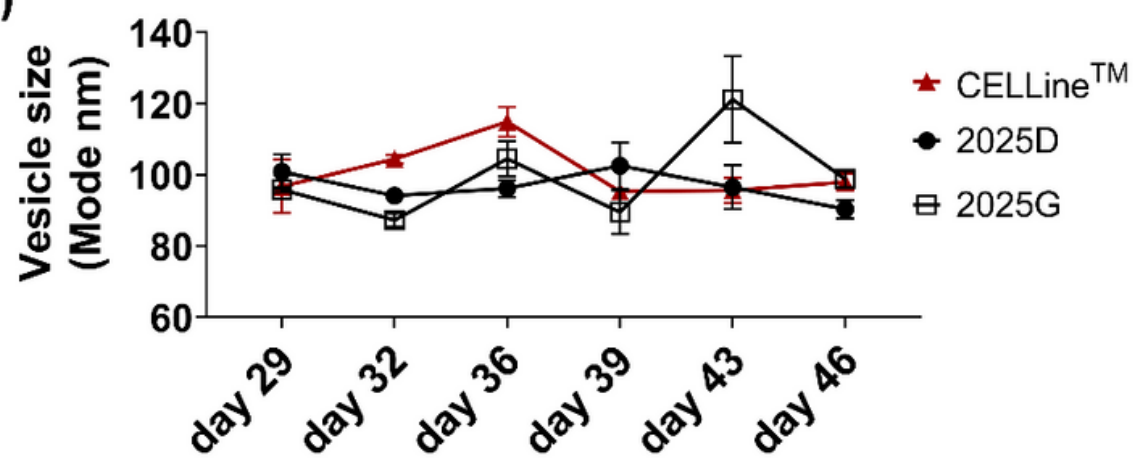

B)

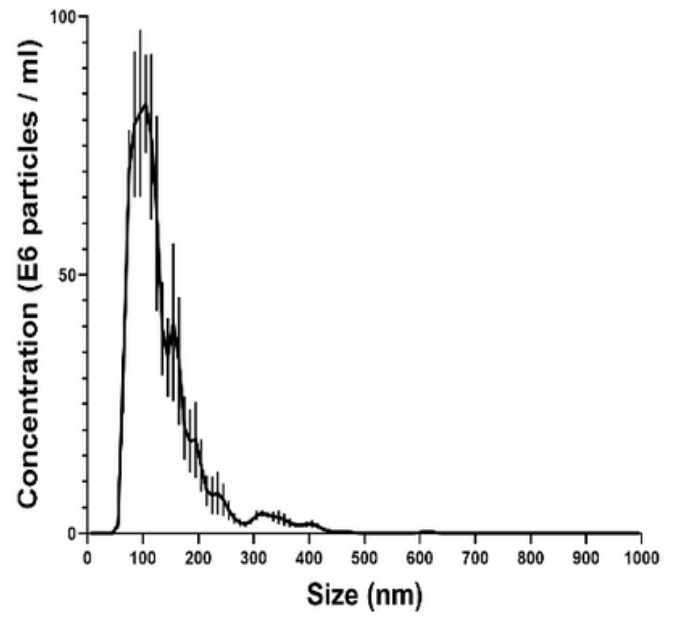

D)

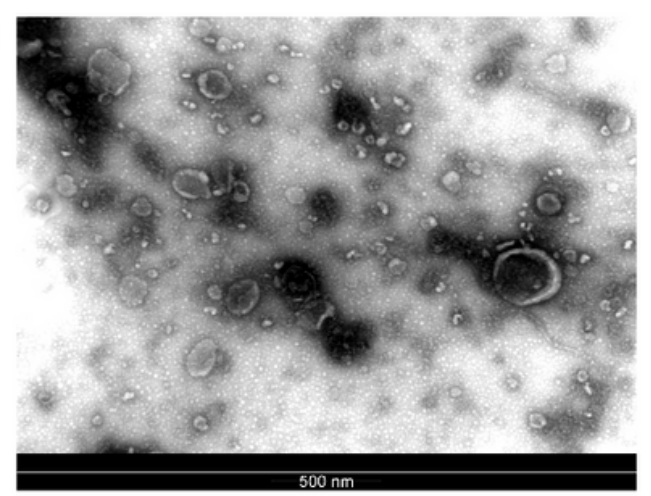

Figure 6

EVs number and size harvested from cultured equine MSCs. A) Daily EV count from cells grown in a T175 flask or bioreactors. B) NTA histogram showing the size of EVs harvested from MSCs grown in a T175 flask. C) Size of EVs harvested from MSCs grown in bioreactors. D) Negative staining TEM of EVs harvested from the equine MSCs. Scale bar, $500 \mathrm{~nm}$.

\section{Supplementary Files}

This is a list of supplementary files associated with this preprint. Click to download.

- MSCEVsandbioreactorsSupplementaltablesandfigures.docx 